\title{
Educação para as Relações Étnico-Raciais: concepções e práticas dos/as docentes da
}

\section{Educação Infantil}

\author{
Education for Ethnic-Racial Relations: conceptions and practices of Early Childhood Education
} teachers

Educación para las Relaciones Étnico-Raciales: concepciones y prácticas de los docentes de Educación Infantil

\author{
Simone Silva Alves \\ ORCID: https://orcid.org/0000-0002-1292-4038 \\ Universidade Federal do Pampa, Brasil \\ E-mail: sialves554@gmail.com \\ Sandra Silva Vieira \\ ORCID: https://orcid.org/0000-0001-5280-1481 \\ Universidade Federal do Pampa, Brasil \\ E-mail: sandravpinto4@gmail.com \\ Vitor Garcia Stoll \\ ORCID: https://orcid.org/0000-0002-4133-9313 \\ Universidade Federal do Pampa, Brasil \\ E-mail: vitorgarciastoll@gmail.com \\ Quelen Colman Espíndola Lima \\ ORCID: https://orcid.org/0000-0001-8343-2279 \\ Universidade Federal de Santa Maria, Brasil \\ E-mail: quelenespindola13@gmail.com
}

\begin{abstract}
Resumo
Esta pesquisa apresenta os resultados de um Trabalho de Conclusão de Curso produzido na Licenciatura em Pedagogia da Universidade Federal do Pampa - Campus Jaguarão/RS. Objetivou-se compreender que concepções e práticas os/as professores/as de uma escola de Educação Infantil do município de Arroio Grande/RS, tem da Educação para Relações Étnico-Raciais tendo como orientação a Lei 10.639/2003. A motivação para a elaboração dessa pesquisa deu-se a partir da reflexão da prática do Estágio Supervisionado e por compreender que esse é o momento fundamental para o acadêmico correlacionar teoria e prática. Metodologicamente apresenta natureza qualitativa e procedimentalmente classifica-se como um estudo de caso. O trabalho de campo foi concretizado durante os meses de setembro e outubro do ano de 2019, sendo os dados empíricos obtidos a partir de entrevista semiestruturada, aplicada com oito professores/as da rede municipal. Os participantes possuíam entre um a 15 anos de trabalho docente. As informações foram analisadas e interpretadas à luz da perspectiva histórico-crítica, tendo como base metodológica a Análise de Conteúdo. Resultados indicaram fragilidade teórico-conceitual dos sujeitos em relação a abordagem da Educação para Relações Étnico-Raciais na Educação Infantil, sinalizando a necessidade da implementação de formações continuadas mais efetivas e a inserção de componentes curriculares especificas em cursos de formação de professores. Para tanto, este estudo pautou-se nas formulações teóricas de Bardin (2016), Caldeira (2010), Rocha (2007), Silva (2018), Cavalleiro (2017), Gomes (2015), Malheiro (2005), Veiga (2013), dentre outros.
\end{abstract}

Palavras-chave: Educação infantil; Educação para as relações étnico-raciais; Formação de professores; Práticas pedagógicas.

\begin{abstract}
This research presents the results of a Course Completion Work produced in the Pedagogy Degree at the Federal University of Pampa - Campus Jaguarão / RS. The objective was to understand which conceptions and practices the teachers of a school of Early Childhood education in the city of Arroio Grande / RS, have of Education for EthnicRacial Relations having as guidance the Law 10.639 / 2003. The motivation for the elaboration of this research was based on the reflection of the practice of the Supervised Internship and by understanding that this is the fundamental moment for the academic to correlate theory and practice. Methodologically, it presents a qualitative nature and is procedurally classified as a case study. The fieldwork was carried out during the months of September and October of the year 2019, with empirical data obtained from a semi-structured interview, applied to eight teachers from the municipal network. The participants had between one and 15 years of teaching work. The information was analyzed
\end{abstract}


Research, Society and Development, v. 10, n. 3, e12810313141, 2021

(CC BY 4.0) | ISSN 2525-3409 | DOI: http://dx.doi.org/10.33448/rsd-v10i3.13141

and interpreted in the light of the historical-critical perspective, based on the Content Analysis methodological basis. Results indicated the theoretical-conceptual weakness of the subjects in relation to the approach to Education for Ethnic-Racial Relations in Early Childhood Education, signaling the need for the implementation of more effective continuous training and the insertion of specific curricular components in teacher training courses. To this end, this study was based on the theoretical formulations of Bardin (2016), Caldeira (2010), Rocha (2007), Silva (2018), Cavalleiro (2017), Gomes (2015), Malheiro (2005), Veiga (2013), among others.

Keywords: Child education; Education for ethnic-racial relations; Teacher training; Pedagogical practices.

\section{Resumen}

Esta investigación presenta los resultados de un Trabajo de Fin de Curso producido en la Licenciatura en Pedagogía de la Universidad Federal de Pampa - Campus Jaguarão / RS. El objetivo fue conocer qué concepciones y prácticas tienen los docentes de una escuela de educación infantil en la ciudad de Arroio Grande / RS, de Educación para las Relaciones Étnico-Raciales teniendo como orientación la Ley 10.639 / 2003. La motivación para la elaboración de esta investigación se basó en la reflexión de la práctica del Pasantía Supervisada y en entender que este es el momento fundamental para que el académico correlacione teoría y práctica. Metodológicamente, presenta un carácter cualitativo y se clasifica procedimentalmente como un estudio de caso. El trabajo de campo se realizó durante los meses de septiembre y octubre del año 2019, con datos empíricos obtenidos a partir de una entrevista semiestructurada, aplicada a ocho docentes de la red municipal. Los participantes tenían entre uno y 15 años de labor docente. La información fue analizada e interpretada a la luz de la perspectiva histórico-crítica, con base en la base metodológica del Análisis de Contenido. Los resultados indicaron la debilidad teórico-conceptual de las asignaturas en relación al abordaje de la Educación para las Relaciones Étnico-Raciales en la Educación Infantil, señalando la necesidad de la implementación de una formación continua más efectiva y la inserción de componentes curriculares específicos en los cursos de formación docente. Para tanto, este estudo pautou-se nas formulações teóricas de Bardin (2016), Caldeira (2010), Rocha (2007), Silva (2018), Cavalleiro (2017), Gomes (2015), Malheiro (2005), Veiga (2013), entre otros.

Palabras clave: Educación infantil; Educación para las relaciones étnico-raciales; Formación de profesores; Prácticas pedagógicas.

\section{Introdução}

Entende-se que o estudo sobre o ensino da história e da cultura afro-brasileira facilita aos estudantes na Educação Infantil a desmitificação do preconceito e do racismo em nossa sociedade. Discutir sobre esse assunto parece polêmico, porém indispensável na formação da identidade das crianças, principalmente as que frequentam as escolas de Educação Infantil.

É notável que o preconceito e o racismo ainda estão presentes em nosso cotidiano, e não é diferente com as crianças pequenas, que muitas vezes, o vivenciam na escola e no âmbito familiar. Além destes ambientes, os meios de comunicação também contribuem para reprodução do racismo ao retratar o negro de maneira marginalizada ou estereotipada, fortalecendo atitudes de hostilidade e injustiças. Compreendemos que a criança não nasce racista, um dos motivos para tal comportamento é a convivência com pessoas preconceituosas.

A despreocupação com a questão da convivência multiétnica, quer na família, quer na escola, pode colaborar para a formação de indivíduos preconceituosos e discriminadores. A ausência de questionamento pode levar inúmeras crianças e adolescentes a cristalizarem aprendizagens baseadas, muitas vezes, no comportamento acrítico dos adultos a sua volta. (Cavalleiro, 2017, p. 20).

Destaca-se que ensinar as crianças sobre a Educação para as Relações Étnicos Raciais, além de imprescindível, é um direito legal no Brasil, conforme exposto na Lei 10.639/2003, que altera a Lei n 9.394/96 que estabelece as Diretrizes e Bases da Educação Nacional para incluir no currículo oficial da rede de ensino a obrigatoriedade da temática "História e Cultura Afro-Brasileira". Mais que conhecer a Lei é necessário colocá-la em prática, pois urge que os/as professores/as estejam preparados através de cursos de formação continuada para abordarem essa temática com os estudantes da Educação Básica.

De acordo com Oliveira e Lindner (2020, p. 4) “(...) a Educação das Relações Étnico-raciais refere-se a processos educativos que favoreçam aos negros e aos não negros construírem uma identidade étnico-racial positiva, possibilitando à 
Research, Society and Development, v. 10, n. 3, e12810313141, 2021

(CC BY 4.0) | ISSN 2525-3409 | DOI: http://dx.doi.org/10.33448/rsd-v10i3.13141

superação dos preconceitos raciais, estimulando a vivência de práticas sociais livres de discriminação".

Neste sentido, é de suma relevância trabalhar essa temática na Educação Infantil, etapa em que as crianças deixam de conviver somente com suas famílias e passam a viver com outros segmentos da sociedade. O contato com diferentes grupos, geralmente, ocasiona curiosidade ao diferente, sendo esse o momento ideal para que os/as professores/as desenvolvam práticas pedagógicas que valorizem a diversidade étnica do Brasil.

Com base no exposto, emergiu o seguinte problema de pesquisa: "Que concepções e práticas os/as professores/as de uma escola de Educação Infantil do Município de Arroio Grande/RS possuem sobre a temática das Relações Étnico-Raciais?”. A delimitação do lócus se justifica, pois uma das autoras é estudante de Licenciatura em Pedagogia e, ao realizar o Estágio Supervisionado nessa modalidade de ensino e na referida escola no ano 2018, percebeu que professores/as da instituição de ensino pouco discutiam a temática, somente era abordada em datas comemorativas, ou em projetos a pedido da coordenação pedagógica. Já o foco na Educação Infantil deu-se por entender que é a partir dessa idade que questões sobre diversidade são necessárias serem dialogadas, principalmente no que tange a ensinar aos/as nossos/as alunos/as uma educação antirracista.

Para responder o questionamento de pesquisa, elencou-se como objetivo geral: compreender que concepções e práticas os/as docentes de uma escola de Educação Infantil do Município de Arroio Grande/RS têm da Educação para Relações Étnico-Raciais.

E como objetivos específicos, buscou-se: (1) entender que visão esses/as profissionais possuem da Educação para Relações Étnico-Raciais, (2) verificar que conhecimentos eles/as têm da Lei $\mathrm{n}^{\circ}$ 10.639/2003, (3) identificar que práticas pedagógicas ou atividades educativas contemplam a Educação para as Relações Étnico-Raciais; (4) e investigar que conhecimentos a formação acadêmica ou formação continuada proporcionou sobre o ensino de história e cultura afro-brasileira aos/as professores dessa escola.

Sendo assim, este artigo foi estruturado em quatro seções específicas, sendo a primeira a introdução. A segunda, apresenta alguns conceitos relevantes para o aprofundamento deste estudo; a terceira, mostra as escolhas metodológicas propostas para desvendar a problemática em questão, os procedimentos para coleta de dados e a descrição do método de análise. Na quarta etapa, são apresentadas as categorias emergentes e sua discussão a luz do referencial teórico. E por fim, são tecidas algumas considerações acerca do percurso.

\section{Fundamentação Teórica}

Compreendemos que a concepção de criança enquanto indivíduo e ser dotado de sentidos e significados específicos é uma construção da sociedade moderna, pois durante muito tempo, suas peculiaridades não eram reconhecidas, sendo diferenciadas dos adultos apenas pela estatura. Na Idade Média, no século XIV, a criança era considerada um adulto em miniatura, pois “( ...) assim que deixava de ser tão dependente dos pais ou ama, era introduzida no mundo adulto e nesse meio ela não era poupada de nada, via e ouvia de tudo" (Souza, 2015, p. 9).

Neste período histórico era comumente a mortalidade infantil, principalmente, nas classes subalternas, onde se acentuava a extrema pobreza e as condições precárias de higiene. As genitoras seguidamente viam seus filhos morrerem por doenças, pois não tinham condições financeiras de tratá-los. Quando atingiam a uma determinada idade era um verdadeiro milagre. As crianças não possuíam uma identidade própria, vindo a tê-la somente ao conseguirem realizar tarefas como os adultos com o qual tinham contato (Caldeira, 2010).

Na França, no século XVIII, em resposta à condição de miséria, abandono e maus tratos de crianças pequenas, cujo os pais trabalhavam em fábricas, fundições e minas; as instituições infantis se tornaram necessárias. Contudo, alguns setores da elite não viam com bons olhos a ideia de educar o proletariado, havendo distinção entre as classes e restringindo a última uma 
Research, Society and Development, v. 10, n. 3, e12810313141, 2021

(CC BY 4.0) | ISSN 2525-3409 | DOI: http://dx.doi.org/10.33448/rsd-v10i3.13141

educação como ato de ocupação e piedade (Gomes, 2015).

Neste contexto, a criança era compreendida como objeto do adulto, pois era depositada nela, através da rigidez, os costumes morais e intelectuais da época. As crianças foram então retiradas do convívio da sociedade dos adultos e colocadas em colégios internos, por meio de uma ação conjunta entre família e escola. Apesar da conquista de sua identidade, a criança pagou um alto preço, pois, ainda continuava sem ter o direito de exercer sua característica principal: ser livre e espontânea (Gomes, 2015).

No Brasil, com a Revolução Industrial, ou seja, com a substituição do uso das ferramentas pelas máquinas, essa transição possibilitou a inserção da mulher no mercado trabalho, essas trabalhadoras necessitaram de um lugar para deixar seus filhos o que ocasionou um grande movimento da classe operária reivindicar por esse espaço, já que as crianças pequenas ficariam muitas horas longe de sua progenitora e necessitando de cuidados específicos. Portanto essas mudanças observadas na organização familiar, nos seus costumes e nos seus hábitos, contribuíram para a ascensão e expansão da educação infantil em nosso país, sobretudo, a partir de 1970,

(...) o nascimento da indústria moderna alterou profundamente a estrutura social vigente, modificando os hábitos e costumes das famílias. As mães operárias que não tinham com quem deixar seus filhos utilizavam o trabalho das conhecidas mães mercenárias. Essas, ao optarem pelo não trabalho nas fábricas, vendiam seus serviços para abrigarem e cuidarem dos filhos de outras mulheres. (Paschoal \& Machado, 2009, p. 80).

Neste sentido, as creches surgem no Brasil com caráter assistencialista no final do século XIX e nas primeiras décadas do século XX, onde seu principal objetivo era o cuidar, não levando em conta as particularidades e especificidades da "criança".

Com a Constituição de 1988 a criança de até seis anos de idade começa a ser vista como um sujeito de direito. Garantido por lei, o ensino obrigatório tornou-se uma prioridade, ao passo que o ensino fundamental tornou-se um direito público subjetivo, isto é, deve ser garantido gratuitamente a todo e qualquer cidadão e sua oferta irregular ou o seu não oferecimento pelo Poder Público importa responsabilidade da autoridade competente (Brasil, 1988).

Outro documento importante a ser citado é o Estatuto da Criança e do Adolescente (ECA), que foi aprovado em 1990 através da Lei 8.069/90, dois anos após a promulgação da Constituição Federal de 1988, que assegura a crianças e adolescentes, através do artigo $3^{\circ}$, os direitos fundamentais inerentes a pessoa humana, para que seja possível o acesso às oportunidades de desenvolvimento integral. Por isso, de acordo com esse instrumento normativo:

A criança e o adolescente gozam de todos os direitos fundamentais inerentes à pessoa humana, sem prejuízo da proteção integral de que trata esta Lei, assegurando-se-lhes, por lei ou por outros meios, todas as oportunidades e facilidades, a fim de lhes facultar o desenvolvimento físico, mental, moral, espiritual e social, em condições de liberdade e de dignidade. (Brasil, 1990, p. 19).

Em 1996 grandes mudanças em relação à educação ocorreram principalmente no que tange as escolas de Educação Infantil, que deixam de ter caráter assistencialista e passam a ser escolas, lugar em que essas serão vistas como um ser histórico e que seus conhecimentos prévios serão levados em conta.

De acordo com a Lei de Diretrizes e Bases da Educação Nacional (1996), a Educação Infantil é a primeira etapa da Educação Básica e tem como objetivo o desenvolvimento integral da criança em seus aspectos, físico, afetivo, psicológico, intelectual e social (Brasil, 1996). Complementar, a Resolução n. 5, de 17 de dezembro de 2009 estabelece que a:

Educação Infantil primeira etapa da educação básica, oferecida em creches e pré-escolas, às quais se caracterizam 
Research, Society and Development, v. 10, n. 3, e12810313141, 2021

(CC BY 4.0) | ISSN 2525-3409 | DOI: http://dx.doi.org/10.33448/rsd-v10i3.13141

como espaços institucionais não domésticos que constituem estabelecimentos educacionais públicos ou privados que educam e cuidam de crianças de 0 a 5 anos de idade no período do dia, em jornada integral ou parcial, regulados e supervisionados por órgão competente do sistema de ensino e submetidos a controle social (Brasil, 2010, p. 12).

Portanto, são nesses espaços educacionais que a criança passa a ter contato com diferentes grupos étnicos. Para Cavalleiro (2017), é nessa etapa que ocorre a primeira socialização no qual será apresentado a este novo membro um mundo com uma configuração pronta, definida, construída antes do seu nascimento.

Nesse sentido, é nas escolas de Educação Infantil que o indivíduo aprende atitudes, opiniões, valores e respeito aos diferentes grupos étnicos. Dessa forma, torna-se necessário que os profissionais da Educação Básica estejam preparados para receberem seus alunos, mostrando através de suas práticas pedagógicas que o cuidar também é um ato educativo, e levem em conta o conhecimento prévio que cada criança traz consigo, pois através do lúdico e da brincadeira podem ser desenvolvidas atividades que perpassem diferentes áreas do conhecimento e atendam as demandas do grupo e da individualidade. Sendo assim, o Referencial Curricular Nacional para a Educação Infantil afirma que

O trabalho direto com crianças pequenas exige que o professor tenha uma competência polivalente. Ser polivalente significa que ao professor cabe trabalhar com conteúdo de naturezas diversas que abrangem desde cuidados básicos essenciais até conhecimentos específicos provenientes das diversas áreas do conhecimento. Este caráter polivalente demanda, por sua vez, uma formação bastante ampla do profissional que deve tornar-se, ele também, um aprendiz, refletindo constantemente sobre sua prática, debatendo com seus pares, dialogando com as famílias e a comunidade e buscando informações necessárias para o trabalho que desenvolve. São instrumentos essenciais para a reflexão sobre a prática direta com as crianças a observação, o registro, o planejamento e a avaliação. (Brasil, 1998, p. 41).

Dessa forma, o espaço educativo torna-se ideal para trabalhar situações cotidianas que ampliem seus conhecimentos, dentre eles, a diversidade étnica, tema que para alguns professores/as parece não ser importante, o que é um equívoco, pois a Lei $n^{\circ}$ 10.639/2003, torna obrigatório a inclusão nos currículos escolares o ensino da História e Cultura Afro-Brasileira. Também se destaca o Referencial Curricular Infantil (2010), que afirma que devem ser trabalhados seis eixos temáticos com crianças até cinco anos, são eles: movimento, música, artes visuais, linguagem oral e escrita, matemática, identidade e autonomia, natureza e sociedade. Outros documentos legais afirmam a obrigatoriedade do estudo dessa temática, dentre eles estão: Diretrizes Curriculares Nacionais para a Educação Infantil, Base Nacional Comum Curricular, Diretrizes Curriculares Nacionais para a Educação das Relações Étnico-Raciais e para o Ensino de História e Cultura Afro-Brasileira e Africana.

Observa-se que mesmo existindo todo esse aparato legal que versam sobre a temática, ainda existem muitos profissionais da educação que o desconhecem, ou por outros motivos não colocam em sua prática pedagógica, talvez por não saber de que maneira vão abordar e debater sobre a Educação para as Relações Étnicos Raciais.

Ressalta-se que, os/as professores/as ao ensinar sobre a Educação para as Relações Étnico-Raciais as crianças, possibilitam que elas conheçam outras culturas, percebendo que todas são importantes e que cada espaço geográfico tem um modo de viver, uma língua a ser falada e, muitas vezes, nós a utilizamos sem saber que é originada de outro povo. Logo, nenhuma cultura é melhor do que a outra e, em especial, a afro-brasileira precisa ser problematizada nos currículos escolares, pois a criança negra muitas vezes tem sobre si uma visão negativa, devido às brincadeiras de mau gosto que sofrem no seu dia a dia e que podem prejudicar no seu processo de ensino e aprendizagem.

Rocha (2007), através de seu livro "Educação das Relações Étnico-Raciais: pensando referenciais para a organização da prática pedagógica" afirma que o seu maior desejo é as crianças negras serem representadas positivamente nos indicadores escolares e que as instituições de ensino estejam preparadas para combater as posturas etnocêntricas em seus currículos, educadores preparados em sua prática pedagógica, dominando os conteúdos sobre essa temática, refletindo sobre os conceitos 
e valores que trazem sobre o negro e sua cultura.

$\mathrm{Na}$ escola as culturas afro-brasileira e indígena são omitidas e o material didático está cheio de conteúdos depreciativos e preconceituosos em relação aos negros e povos indígenas, o que pode contribuir para o fracasso escolar dos alunos pertencentes a esse grupo. (Silva, 2018. p. 132).

Destaca-se que, outro documento importante é o Projeto Político Pedagógico (PPP), que reflete a proposta educacional de ensino e que deve ser elaborado por todas as escolas segundo a Lei de Diretrizes e Bases da Educação Nacional (Brasil, 1996). Compreende-se que para alcançar os objetivos propostos pelos instrumentos normativos, é preciso considerar fatores que são determinantes, dentre eles, a realidade sociopolítica e econômica de cada contexto histórico, a clareza quanto ao que se pretende com a educação, que cidadão se pretende formar e que se sociedade se pretende construir.

Conforme Veiga (2003), o PPP serve para nortear as atividades de uma escola, seja na gestão, administração ou orientação pedagógica. Esse documento possui como objetivo principal não só romper com paradigmas em relação à metodologia ou se discutir decisões, busca a inclusão, a coerência e o comprometimento, colocando todos/as os/as envolvidos/as como responsáveis por esse trabalho que é de esperanças e incertezas.

Salienta-se que as mudanças ocorridas na legislação educacional brasileira trouxeram maior autonomia as escolas através das reformas educacionais ocorridas ao longo dos anos, sendo o PPP uma delas. De acordo com Veiga (2013, p. 12), "ao construirmos os projetos de nossas escolas, planejamos o que temos a intenção de fazer, de realizar. Lançamo-nos para diante, com base no que temos, buscando o possível".

Assim sendo, o PPP é construído a partir da realidade, em busca do melhoramento na qualidade do ensino, que é o principal objetivo das escolas, através de metas que devem ser seguidos por todos os envolvidos na instituição educativa.

Para que esse projeto possa ser realizado com a colaboração de todos é preciso que a escola tenha uma gestão democrática, ou seja, são necessários métodos democráticos para sua concretização. Consoante Malheiro (2005, p. 81), "a atitude democrática é necessária, mas não suficiente. Precisamos de métodos democráticos que atendam ao efetivo exercício da democracia". O autor também enfatiza ser fundamental que a gestão escolar tenha um perfil inovador, democrático, coletivo e comprometido (Malheiros, 2005).

Nesse sentido, a construção do PPP deve ser baseada na realidade em que a escola vive. É vital conhecer os diferentes sujeitos que nela estão presentes, para compreender quais são as suas necessidades, os conflitos existentes, e assim poder encontrar os objetivos e analisar quais serão os meios para alcançar esses fins dentro da instituição educacional. Como afirma Veiga \& Resende (2008, p. 09): "Ele [o PPP] precisa ser concebido com base nas diferenças existentes entre seus autores, sejam eles professores, equipe técnico-administrativa, pais, alunos e representantes da comunidade local. É, portanto, fruto de reflexão e investigação"

No PPP da escola pesquisada, a Educação para as Relações Étnico Raciais é contemplada como um de seus princípios: "Que se valorize, e reconheça as culturas africanas, afro-brasileiras e se combata o racismo e discriminação". Embora não faça referência explícita a Lei $n^{\circ}$ 10.639/2003, o trecho apresenta, ainda que incipiente, uma proposta inclusiva: a relevância de ensinar as crianças sobre diversidade, combatendo quaisquer tipos de discriminação e preconceito, e acima de tudo formar indivíduos que respeitem as diferenças entre as pessoas.

Por fim, demarca-se que as Diretrizes Curriculares Nacionais para as Relações Étnico Raciais da Educação Infantil afirmam que: "O papel da educação infantil é significativo para o desenvolvimento humano, para a formação da personalidade, para a construção da inteligência e para a aprendizagem" (Brasil, 2013, p. 48-49). Neste sentido, discutir essa temática de estudo requer conhecimento, sensibilidade e capacitação por parte dos/as professores/as. Precisa-se da apropriação de 
conceitos e práticas pedagógicas que propiciem um ambiente que estimule o respeito às diversidades e que levem a formação de cidadãos/ãs de bem preocupados/as com a coletividade, e acima de tudo que não desprezem nenhuma cultura em detrimento de outra.

\section{Metodologia}

Essa investigação caracterizou-se quanto à natureza como qualitativa, pois foram consideradas as percepções, as atitudes e as ações de um determinado grupo, tendo como fulcro a interpretação do porquê de ter obtido determinada constatação (Minayo, 2017). No que se refere aos procedimentos, trata-se de um estudo de caso: “(...) estudo profundo e exaustivo de um ou poucos objetos, de maneira que permita seu amplo e detalhado conhecimento" (Gil, 2017, p. 54). Neste caso, o grupo restringiu-se aos/as professores/as de uma escola municipal da Educação Infantil de Arroio Grande/RS, instituição que uma das pesquisadoras desenvolveu o Estágio Supervisionado.

Os dados empíricos foram obtidos por meio de entrevista semiestruturada, composta por dez questões, aplicada a oito professores/as nos meses de setembro e outubro de 2019. E a análise pautou-se na Análise de Conteúdo descrita por Bardin (2016), que consiste em três distintas etapas: (a) pré-análise, (b) exploração do material (c) e tratamento dos resultados, inferência e interpretação. A partir das quais, emergiram as categorias expostas no Quadro 1:

Quadro 1 - Categorias emergidas a partir da análise dos dados.

\begin{tabular}{|c|c|c|}
\hline Categoria & Descrição & Perguntas analisadas \\
\hline \multirow{3}{*}{$\begin{array}{l}\text { Perfil dos } \\
\text { pesquisados }\end{array}$} & \multirow{3}{*}{$\begin{array}{c}\text { Descreve o perfil dos sujeitos da pesquisa } \\
\text { quanto ao gênero, idade e tempo de docência } \\
\text { na Educação Infantil e formação. }\end{array}$} & Qual sua idade e gênero? \\
\hline & & Quantos anos você trabalha na Educação Infantil? \\
\hline & & Qual a sua formação? \\
\hline \multirow{2}{*}{ Concepção docente } & \multirow{2}{*}{$\begin{array}{l}\text { Apresenta a concepção dos/as professores/as } \\
\text { sobre a Lei } n^{\circ} 10.639 / 2003 \text {. }\end{array}$} & Você conhece a Lei $\mathrm{n}^{\circ}$ 10.639/2003? \\
\hline & & O que você sabe sobre essa lei? \\
\hline \multirow{2}{*}{$\begin{array}{l}\text { Prática docente } \\
\text { para as Relações } \\
\text { Étnico-Raciais }\end{array}$} & \multirow{2}{*}{$\begin{array}{c}\text { Discute as formas que os sujeitos da } \\
\text { pesquisa abordam as Relações Étnico- } \\
\text { raciais. }\end{array}$} & $\begin{array}{l}\text { Você trabalha o ensino da história da cultura afro- } \\
\text { brasileira com os/as educandos/as? }\end{array}$ \\
\hline & & $\begin{array}{l}\text { Que práticas pedagógicas ou atividades educativas } \\
\text { você desenvolve com essa temática em sala de aula? }\end{array}$ \\
\hline \multirow[t]{2}{*}{$\begin{array}{l}\text { Racismo na } \\
\text { Educação Infantil }\end{array}$} & \multirow{2}{*}{$\begin{array}{c}\text { Apresenta se os sujeitos da pesquisa já } \\
\text { presenciaram alguma forma de racismo entre } \\
\text { os/as educandos/as da Educação Infantil e a } \\
\text { forma como procederam. }\end{array}$} & $\begin{array}{c}\text { Na sua rotina de trabalho você já se deparou com } \\
\text { alguma atitude preconceituosa de racismo entre os/as } \\
\text { educandos/as em sala de aula? }\end{array}$ \\
\hline & & Como você age com essas situações? \\
\hline $\begin{array}{l}\text { Formação de } \\
\text { professores/as }\end{array}$ & $\begin{array}{l}\text { Discute a relevância da formação de } \\
\text { professores para as relações étnico-raciais e } \\
\text { necessidade da formação continuada. }\end{array}$ & $\begin{array}{c}\text { Durante sua formação acadêmica ou formação } \\
\text { continuada de professor/a você teve informações, } \\
\text { conhecimentos específicos sobre o ensino de história } \\
\text { da cultura afro-brasileira? }\end{array}$ \\
\hline
\end{tabular}

Fonte: Autores (2021).

A seguir é apresentada a discussão dos resultados a partir de referenciais que dialogam com a temática e de quadros que destacam as informações obtidas na análise.

\section{Resultados e Discussões}

Participaram da pesquisa oito professores/as: sete mulheres e um homem, com idades entre 30 e 55 anos. Destes, seis possuem formação inicial em Licenciatura em Pedagogia e os/as outros/as dois/duas em Letras e Biologia. Além disso, cinco têm Curso Normal e seis são pós-graduados/as: quatro em Educação Infantil, um/a em Orientação e Supervisão Escolar e outro/a em Supervisão Escolar e Turismo. A atuação docente varia entre um a 15 anos, informações expostas no Quadro 2: 
Research, Society and Development, v. 10, n. 3, e12810313141, 2021

(CC BY 4.0) | ISSN 2525-3409 | DOI: http://dx.doi.org/10.33448/rsd-v10i3.13141

Quadro 2 - Formação dos sujeitos da pesquisa.

\begin{tabular}{|c|c|c|c|c|c|}
\hline Docente & Idade & Curso Normal & Licenciatura & Pós-Graduação & Docência na Ed. Infantil. \\
\hline PA & 30 & Sim & Pedagogia & Educação Infantil & 4,5 anos \\
\hline PB & 34 & Sim & Pedagogia & - & 2 anos \\
\hline PC & 43 & - & Pedagogia & Orient. e Supervisão Escolar & 8 anos \\
\hline PD & 47 & Sim & Pedagogia & Supervisão Escolar e Turismo & 1,5 anos \\
\hline PE & 44 & - & Pedagogia & Educação Infantil & 15 anos \\
\hline PF & 47 & - & Pedagogia & - & 6 anos \\
\hline PG & 44 & Sim & Biologia & Educação Infantil & 8 anos \\
\hline PH & 55 & Sim & Letras & Educação Infantil & 7 anos \\
\hline
\end{tabular}

Fonte: Autores (2021).

O perfil dos/as pesquisados/as evidencia majoritariamente a presença de mulheres na Educação Infantil, condizente com o cenário educacional atual. Segundo estudo desenvolvido pelo Instituto Nacional de Estudos e Pesquisas Educacionais Anísio Teixeira (INEP) no ano de 2017, $81 \%$ do professorado brasileiro são mulheres, quantitativo que chega a $96 \%$ na Educação Infantil.

Historicamente, no Brasil Colônia, a profissão estava em poder dos homens, pois os jesuítas eram os responsáveis pela educação e administração nas escolas brasileiras, enquanto as mulheres cuidavam do trabalho doméstico, tais como, bordar, cozinhar, cuidar da casa e da família. A discussão em torno da feminização do Magistério é sem dúvida bastante complexa, a mulher que antes cuidava dos afazeres domésticos passa a ser a responsável pela educação das crianças por sua imagem ser associada à função de mãe e esposa. Conforme afirma Schaffrath (2000, p. 10): “A profissionalização da mulher no magistério público deu-se em meio ao entendimento de que a educação escolar era uma extensão da educação dada em casa. (...) As mulheres, mães e educadoras por natureza, passavam agora a estender sua função para as escolas na profissão de professoras".

É pertinente destacar que a profissão, além de ter em seu campo de atuação a maior parte do público feminino, há também desvalorização salarial praticamente em toda a sua história. Possivelmente os salários inferiores foram fator determinante para que os homens desistissem da carreira do Magistério e fossem a procura de outro trabalho, já que socialmente eram considerados chefes de família (Schaffrath, 2000).

Ao analisar a idade dos/as professores/as (30 a 55 anos), infere-se que há pouca inserção de jovens na carreira do Magistério e na Licenciatura em Pedagogia na escola pesquisada, condizendo com o relatório divulgado pela Organização para a Cooperação e Desenvolvimento Econômico (OCDE), em 2018. A pesquisa mostra que a porcentagem de estudantes que querem ser professor/a está diminuindo ao longo dos anos: 5,5\% em 2006, 4,2\% em 2015 e 2,2\% em 2018. Supõe-se que os baixos salários, a falta de infraestrutura e de materiais didáticos, as turmas superlotadas, o estresse e a falta de cursos de formação continuada são alguns aspectos que podem corroborar com o desinteresse dos/as jovens neste ofício.

Ainda com base no Quadro 2, outro fator que chama a atenção é que os/as dois/duas professores/as sem formação inicial em Pedagogia são pós-graduados/as em Educação Infantil. Tal evidência mostra que a formação continuada é um caminho para novos conhecimentos e atualizações, podendo ser um processo de reflexão sobre sua práxis nessa modalidade de ensino. Entendemos esse tipo de formação como urgente e necessária não meramente para desenvolver artefatos técnicos, mas, principalmente como espaço para o diálogo, a reflexão e a troca de experiências (Silva \& Oliveira, 2014).

Alguns/as professores/as possuem enraizada a associação de que a formação continuada é constituída meramente por cursos expositivos e dialogados, porém, esse paradigma precisa ser desconstruído. A ideia-chave da formação continuada é: "colocar a escola como local de aprendizagem da profissão de professor significa entender que é na escola que o professor desenvolve saberes e as competências do ensinar, mediante um processo ao mesmo tempo individual e coletivo". (Libânio, 
2004, p. 34-35 apud Silva \& Oliveira, 2014, p. 74).

Em relação à concepção sobre a Lei no $\mathbf{1 0 . 6 3 9 / 2 0 0 3}$, quatro professores/as (PA, PB, PC e PE) afirmaram que não conhecem a legislação, dois/duas (PD e PG) acreditam ter um conhecimento superficial e apenas um/a (PH) a conhece.

Ao analisar parte do discurso de PA, “(...) só me lembro dessa lei no caso que trouxeram para gente trabalhar essa temática né nas escolas”, observa-se que já ouviu falar sobre a Lei 10.639/03, pois afirma em seu discurso que a temática já foi desenvolvida na escola. No entanto, sugere-se desinteresse do mesmo sobre a questão, já que ao analisar o PPP da instituição de ensino pesquisada, há referências sobre o estudo para a Educação para as Relações Étnicos Raciais na Educação Infantil. Nesse sentido, como já mencionado, esse espaço educacional tem como um dos seus princípios: "Que se valorize, e reconheça as culturas africanas, afro-brasileiras e se combata o racismo e discriminação".

Portanto, supõe-se que esse assunto já deveria permear as práxis desse/a professor/a, pois no PPP da escola está explicito essa temática, assim como afirma Conselho Nacional de Educação/Conselho Pleno na Diretrizes Curriculares Nacionais para a Educação das Relações Étnico-Raciais e para o Ensino de História e Cultura Afro-Brasileira e Africana.

Este parecer visa a atender os propósitos expressos na Indicação CNE/CP 6/ 2002, bem como regulamentar a alteração trazida à Lei 9.394/96 de Diretrizes e Bases da Educação Nacional, pela Lei 10.639/2003, que estabelece a obrigatoriedade do ensino de História e Cultura Afro-Brasileira e Africana na Educação Básica. Desta forma, busca cumprir o estabelecido na Constituição Federal nos seus Art. 5º I, Art. 210, Art. 206, I, § $1^{\circ}$ do Art. 242, Art. 215 e Art. 216, bem como nos Art. 26, 26 A e 79 B na Lei 9.394/96 de Diretrizes e Bases da Educação Nacional, que asseguram o direito à igualdade de condições de vida e de cidadania, assim como garantem igual direito às histórias e culturas que compõem a nação brasileira, além do direito de acesso às diferentes fontes da cultura nacional a todos brasileiros. (Brasil, 2004, p. 9).

Já PB tem a seguinte visão sobre a categoria analisada: "Seria uma cultura que a gente tem que ensinar para os alunos que somos todos iguais e que não devemos ter como diz excluir ninguém tem que ter a inclusão dentro da sala de aula, somos iguais" (PB).

No excerto, percebe-se o desconhecimento sobre a Lei, principalmente ao afirmar que somos todos iguais, pois cada pessoa tem características físicas, psicológicas, sociais e econômicas diferentes. Possivelmente PB se refira à igualdade de direitos, ainda utopia no Brasil. A exemplo, mesmo ancorado em políticas públicas afirmativas de ingresso no Ensino Superior, um estudante negro dificilmente terá acesso ou permanência numa universidade. Neste sentido, cabe ao Estado promover e incentivar políticas de reparações, no que cumpre ao disposto na Constituição Federal, Art. 205, que assinala o dever do Estado de garantir indistintamente, por meio da educação, iguais direitos para o pleno desenvolvimento de todos e de cada um, enquanto pessoa, cidadão ou profissional (Brasil, 1988).

Semelhante ao PB, PE respondeu que “(...) os/as professores/as devem ensinar as crianças desde a Educação Infantil a cultura afro, mostrando que somos iguais em direitos, mas temos características diferentes" (PE). Ressalta-se que ao afirmar que somos iguais em direitos, mesmo esses estando garantidos na Constituição, ainda se identificam desigualdades sociais em relação à população negra, principalmente no que se refere à educação (Rocha, 2007).

Segundo Rocha (2007), a reprovação nas instituições públicas demonstra que há uma estreita relação entre a educação escolar e as desigualdades raciais na sociedade brasileira. É preciso considerar que essa estrutura rígida é inadequada à população negra e pobre desse país.

Já o discurso do PC, “(...) a gente tem que inserir todas as formas de livros, histórias, trabalhar as diversidades com eles né de forma lúdica, sempre incluindo temas sobre a temática étnico racial" (PC), faz referências a alguns recursos para abordar o assunto, o que parece pertinente. No entanto, o modo de como conduzir essa questão com crianças pequenas, não fica explícito em sua fala, o que faz repensar a prática docente sobre a Educação para as Relações Étnico Raciais. As Diretrizes 
Curriculares Nacionais para a Educação Infantil no que se refere a proposta pedagógica e diversidade afirma: As propostas pedagógicas das instituições de Educação Infantil deverão prever condições para o trabalho coletivo e para a organização de materiais, espaços e tempos que assegurem “(...) o reconhecimento, a valorização, o respeito e a interação das crianças com as histórias e as culturas africanas, afro-brasileiras, bem como o combate ao racismo e à discriminação" (Brasil, 2010, p. 21).

De modo geral, evidencia-se que PA, PB, PC e PE, expressam-se de maneira equivocada no que se refere a Lei $\mathrm{n}^{\circ}$ 10.639/2003. Embora falem em igualdade e diversidade, não deixam explícito as questões Étnico-Raciais no currículo, diferente de PH que demonstrou ter conhecimento sobre o assunto, conforme excerto.

Eu sei que esta lei trata da inserção do ensino da história da cultura afro-brasileira na Educação Infantil, até os anos finais do ensino fundamental, o que posso te dizer é que antes dessa lei entrar em vigor eu já trabalhava a questão afro com meus alunos, porque o negro ele é discriminado, só nós sentimos na pele o preconceito e a discriminação racial, embora muitos digam que não existe. Eu sou negra com muito orgulho, e por sofrer discriminação racial procurei trabalhar com os alunos dos anos iniciais aos anos finais a cultura afro-brasileira para que eles conheçam e compreendam a importância dos africanos e o quanto contribuíram na música, na culinária, na arte, dança, linguagem, para que as crianças e adolescentes se aceitem positivamente como são. Quando trabalhei sobre a cultura afro, com certeza fui trabalhando as outras culturas ressaltando a importância de todas, porque muitas pessoas dizem que quando falamos que existe uma lei obrigatória que trata da questão étnico-racial, que devemos levar ao conhecimento de nossos educandos a importância dos africanos nós professores deixamos de lado as outras culturas, o que não é verdade. (PH).

Salienta-se que a Educação para as Relações Étnico-Raciais é uma temática bastante discutida por muitos teóricos do campo da educação e também é respaldada por leis nacionais, como a Lei no 10.639/2003, que afirma a pertinência do seu debate e abordagem na Educação Básica para a superação de ações discriminatórias que criam uma imagem social inferiorizada do negro. Graças à luta dos movimentos sociais, em especial do Movimento Negro, essa vitória foi conquistada. Apesar de ser recente há muitos caminhos a serem percorridos até que realmente se efetive. Cabe aqui destacar que outros documentos também norteiam essa temática, dentre eles, está a implementação das Leis e Diretrizes para a Educação ÉtnicoRacial.

Ao analisar a categoria Prática Docente para as Relações Étnico-Raciais na Educação Infantil, seis professores/as afirmaram abordar a temática em sala de aula e dois/duas responderam às vezes. Dentre eles/as, PD e PE abordam somente em datas comemorativas, conforme se evidencia nos trechos: “(...) é mais nas datas comemorativas né, dia 22 de novembro né, a Consciência Negra. (...) durante o ano a gente, vou ser sincera, fica de lado” (PE), “(...) Em novembro sim, projeto da semana da Consciência Negra sempre se trabalha alguma coisa" (PD).

Quanto à forma de abordagem, foram identificadas as seguintes: histórias (07), roda de conversa (04), filmes (02), pintura (01), desenho (01) e recorte e colagem (01), conforme expresso no Quadro 3:

Quadro 3 - Abordagem das Relações Étnico-raciais na prática docente dos sujeitos.

\begin{tabular}{|c|c|c|c|c|c|c|c|}
\hline \multirow{2}{*}{ Docente } & \multirow{2}{*}{$\begin{array}{c}\text { Trabalha o Ensino da Histório da } \\
\text { Cultura Afro-Brasileira? }\end{array}$} & \multicolumn{6}{|c|}{ Forma de abordagem } \\
\hline & & Histórias & Conversas & Filme & Pintura & Desenhos & Recorte \\
\hline PA & Sim & $\mathrm{X}$ & & & & & \\
\hline $\mathrm{PB}$ & Sim & $\mathrm{X}$ & & & & & \\
\hline $\mathrm{PC}$ & Sim & $X$ & & & & & \\
\hline $\mathrm{PD}$ & Às vezes & $\mathrm{X}$ & & & $\mathrm{X}$ & & \\
\hline $\mathrm{PE}$ & Às vezes & $\mathrm{X}$ & $\mathrm{X}$ & & & & \\
\hline $\mathrm{PF}$ & Sim & & $\mathrm{X}$ & $\mathrm{X}$ & & $X$ & \\
\hline $\mathrm{PG}$ & Sim & $\mathrm{X}$ & $X$ & & & & $\mathrm{X}$ \\
\hline $\mathrm{PH}$ & Sim & $\mathrm{X}$ & $\mathrm{X}$ & $\mathrm{X}$ & & & \\
\hline
\end{tabular}

Fonte: Autores (2021). 
Percebeu-se que a contação de histórias é quase unânime para abordar a temática entre os/as professores/as. A exemplo, PB relata:

(...) já trabalhei com a história da Menina Bonita do Laço de Fita. Contei a história pra eles, fiz os bonecos também. Existem várias cores que nenhum somos iguais e aí para eles vê e botar as mãos, um com a mão aberta um do lado do outro para eles vê que nenhuma mão é igual a mesma cor, de várias formas, sempre em forma de história, para fixar esse tema melhor com a criança (PB).

Destaca-se que a partir desse recurso, as crianças podem observar as ilustrações, interagir umas com as outras e com o educador. Contudo, observa-se em seu discurso pouco domínio sobre a Educação para as Relações Étnico-Raciais, o que poderia ser minimizado através de cursos de formação continuada.

Já o discurso de PE exemplifica uma das técnicas desenvolvidas na roda de conversa, segundo recurso mais citado: (...) a gente conversa com a criança sobre as características, a gente se observa em frente do espelho, quais as diferenças, características de cada um, que todos independente disso ai são todos iguais, eles são pequenos e a gente trabalha sucinto por causa da idade (PE).

Salienta-se o cuidado sobre a concepção de que todos são iguais, pois ao se observarem, as crianças podem facilmente concluir que tem traços diferentes dos colegas. Numa dinâmica como essa, deve ser valorizada a formação biológica, de modo que, haja a compreensão da construção de uma identidade positiva sobre si mesmo. De acordo com Cavalleiro (2017):

Identidade refere-se a um contínuo sentimento de individualidade que se estabelece valendo-se de dados biológicos e sociais. O indivíduo se identifica reconhecendo seu próprio corpo, situado em um meio que o reconhece como ser humano e social. Assim a identidade resulta da percepção que temos de nós mesmos, advinda da percepção que temos como os outros nos vêem (Cavalleiro, 2017, p. 19).

Por fim, chama a atenção, a ausência do teatro e dos jogos didáticos: o primeiro oportuniza a interação, e estimula a criatividade através da interpretação de diferentes personagens; e o segundo, pauta-se no lúdico como possibilidade de aprendizagem. Segundo a Base Nacional Comum Curricular para a Educação Infantil, um dos eixos estruturantes que levam em conta esse assunto é “o eu, o outro e nós”, pois é na interação com os pares e com adultos que as crianças vão constituindo um modo próprio de agir, sentir e pensar e vão descobrindo que existem outros modos de vida, pessoas diferentes, com outros pontos de vista (Brasil, 2017).

Na categoria racismo na Educação Infantil, foi indagado aos entrevistados se alguma vez presenciaram atitudes de racismo em sala de aula, na qual, PA respondeu: "Sim, sim, mesmo trabalhando os valores, eles sempre têm esse tipo de preconceito. Vêm de casa né, esses valores vêm de casa e as crianças não trabalham” (PA). Outros seis professores/as afirmaram não ter vivenciado em seu âmbito de trabalho.

Salienta-se que o racismo e a discriminação estão presentes nos diversos espaços, muitas vezes, advindos da convivência social das crianças. A escola não está imune a esse tipo de conduta, pois o racismo se constitui como uma “(...) ideologia que permite o domínio sobre um grupo, por exemplo, judeu, negro ou muçulmano, pautado apenas em atributos negativos, imputados a cada um deles. Assim, o racismo atribui a inferioridade a uma raça e está baseado em relações de poder, legitimadas pela cultura dominante". (Cavalleiro, 2017, p. 22).

Em especial, as escolas de Educação Infantil são espaços de acolhimento, onde o cuidar e o ensinar são indissociáveis, sendo o conviver, brincar, participar, explorar, expressar e conhecer-se direitos de aprendizagem assegurados pela BNCC (Brasil, 2017). Para Cavalleiro (2017), a discriminação étnica acontece a partir do momento que são dadas condições de suposta igualdade para um determinado grupo social, educacional e profissional. Desse modo, nesses ambientes, a prática de discriminação é comum, pois diferentes realidades, grupos sociais e étnicos ficam próximos. 
Outros/as professores/as ( $\mathrm{PC}, \mathrm{PD}$ e $\mathrm{PF}$ ) negaram qualquer comportamento racista por parte das crianças, que são incapazes de senti-lo devido sua inocência: "Que eu lembre não, (...) até porque a gente trabalha assim com a faixa etária que eles são bem inocentes, eles não têm ainda essa maldade, essas formas de julgamento” (PC), “(...) os alunos são pequenos né, com certeza assim posso dizer isso não acontece dentro da nossa escola" (PD), "Não, até mesmo porque eu trabalho com Educação Infantil e as crianças não têm essa maldade, a maldade tá na cabeça dos maiores” (PF).

Parece impossível que num espaço com contingente expressivo de pessoas com realidades adversas não exista conflitos sobre esse tema. Supõe-se que haja um silenciamento dos atos racistas e discriminatórios nesse educandário por não saberem como lidar ou não o perceberem. O “(...) silenciamento é uma das ações, atitudes, estratégias adotadas pela escola brasileira para o enfrentamento do racismo”, na qual, “(...) os professores/as não costumam intervir diante de conflitos que agridem crianças negras" (Silva, 2018, p. 131).

Destaca-se também, o relato que $\mathrm{PH}$, que afirma que não presenciou atos de racismo entre os estudantes. Todavia, sofreu racismo de uma criança por influência da família.

$\mathrm{Na}$ Educação Infantil nunca percebi nada das crianças umas com as outras porque eles são pequenos e muito inocentes, porém tinha um aluno que não gostava de vir à aula porque não gostava de mim, então um dia conversando com a criança descobri que os pais assustavam ele dizendo que as pessoas negras eram bravas e pegavam as crianças, portanto o preconceito era do aluno comigo por influência da família $(\mathrm{PH})$.

Observa-se a concepção de que ninguém nasce racista, muito menos as crianças, elas "aprendem a ser". Segundo Cavalleiro (2017), o processo de socialização do indivíduo pode influenciar na maneira que a criança, o jovem e o adulto se comporta nos diversos ambientes que frequenta. As atitudes, as crenças e os valores demonstrados por eles pode ser consequência do que aprenderam com seus familiares, amigos e profissionais que atuam na escola.

Por fim, na categoria Formação de Professores/as, quatro pesquisados/as negaram ter conhecimentos específicos sobre o Ensino da História e da Cultura Afro-brasileira em sua formação acadêmica. Notou-se, no decorrer das entrevistas, que PH, mesmo não tendo estudado a temática durante a graduação, foi a única que se empoderou, demonstrando domínio teóricoconceitual.

Outros/as quatro (PB, PF, PA e PC) responderem ter contato com o assunto na formação inicial ou continuada, mas indicaram fragilidades em seus relatos, indicativos que questionam a qualidade da formação. Conforme corroboram Gomes, Oliveira e Souza (2010, p. 62) "os educadores e as educadoras brasileiras não receberam na sua educação e formação de cidadãos, de professores/as e educadores/as o necessário preparo para lidar com o desafio da problemática da convivência com a diversidade".

Por fim, de acordo com a pesquisa efetuada na referida escola do município de Arroio Grande, fica explícito nas falas de alguns dos entrevistados a necessidade de cursos de formação continuada para que se coloque em prática uma educação antirracista.

\section{Considerações Finais}

A questão norteadora que orientou essa pesquisa foi: "Que concepções e práticas os/as professores/as de uma escola de Educação Infantil do Município de Arroio Grande/RS possuem sobre a temática das Relações Étnico-Raciais?”. Para responder esse questionamento, torna-se essencial retomar pontos significativos a fim de evidenciar se objetivos específicos foram ou não alcançados.

A partir das inferências apurou-se a fragilidade da formação inicial ou continuada dos/as professores/as em relação ao 
Research, Society and Development, v. 10, n. 3, e12810313141, 2021

(CC BY 4.0) | ISSN 2525-3409 | DOI: http://dx.doi.org/10.33448/rsd-v10i3.13141

estudo para Educação das Relações Étnico-Raciais, assunto que precisa ser discutido com as crianças da Educação Infantil, tendo como marco legal a Lei n. 10.639/03, que estabelece a obrigatoriedade de inserir nos currículos escolares conteúdos referentes à história e cultura afro-brasileira e dos povos indígenas brasileiros. Da totalidade de sujeitos, apenas um demonstrou conhecimento sobre a Lei em específico e outros dois a destacaram de forma vaga e generalista.

No que tange a abordagem das Relações Étnico-Raciais na prática docente, a contação de histórias foi a principal atividade utilizada pelos/as professores/as para contemplá-la na Educação Infantil. A partir dela é possível criar personagens, utilizar elementos corporais e entonação de voz para ampliar as possibilidades de interatividade dos estudantes com o assunto em voga. Ainda assim, há de se considerar a faixa etária das crianças para a escolha do livro e priorizar enredos que incentivem a diversidade étnico-racial.

Também é preciso que o docente tenha em seu ambiente de trabalho, atividades didáticas pedagógicas que mostre positivamente a cultura afro-brasileira, que busque um repertório diferenciado, sendo as rodas de conversa, os filmes, as pinturas, os desenhos e os recortes outros recursos destacados pelos sujeitos da pesquisa.

Apesar da variabilidade, percebeu-se - de modo geral - superficialidade na descrição da forma como abordam o tema em sala de aula, havendo nos discursos pouco domínio teórico-conceitual sobre a Educação para as Relações Étnico-Raciais, o que pode comprometer ou tornar menos eficaz a abordagem.

Salienta-se que três pesquisados/as admitiram não ter conhecimentos específicos sobre o Ensino da História e da Cultura Afro-brasileira em sua formação acadêmica e outros quatro tiveram o tema raramente discutido na formação inicial. Tais indicativos poderiam ser minimizados através de cursos de formação continuada e também, sinalizam a importância da inserção de componentes específicas nas licenciaturas.

Desse modo, constata-se que é essencial compreender que algumas categorias são básicas para entender o tema apresentado e que é de suma relevância correlacioná-las com o campo científico da educação. Logo, a categoria Formação de Professores/as torna-se fundamental para viabilizar a formação cidadã aos/as discentes.

Destacamos como desafio, ampliar a representatividade das demais pertenças negras no cotidiano escolar, mostrar aos/as alunos/as que vivemos em um país multicultural, onde existem diversas culturas presentes, mas embora se discuta e se fale em preconceito e racismo, estes se encontram presentes, sobretudo na cultura afro-descendente.

Neste sentido, identificamos que a lógica do diálogo é uma das categorias centrais para abolir o silêncio e o ocultamento dos sujeitos, ou seja, trabalhar com o ensino da História e da Cultura Afrodescendente é primordial, tanto na escola quanto na formação de professores, para acabarmos com as diferentes formas de preconceitos e discriminações que ainda insistem em permear nossas instituições educacionais.

Por fim, demarca-se que nas últimas décadas estudos sobre a Educação para as Relações Étnico-Raciais no âmbito escolar tem ganhado cada vez mais relevância, com as leis nacionais que regem a educação brasileira bem como outros documentos legais que foram citados ao longo dessa investigação. Sendo assim, pesquisas como a aqui apresentada devem ser aprofundadas e aplicadas em diferentes contextos, pois podem trazer importantes contribuições no sentido de legitimar e fomentar práticas pedagógicas de combate ao racismo e com vistas ao reconhecimento e valorização das diversas manifestações culturais e dos conhecimentos produzidos oriundos de diferentes grupos étnico-raciais.

\section{Referências}

Bardin, L. (2016). Análise de conteúdo. Edições 70.

Brasil (1988). Constituição da República Federativa do Brasil de 1988. Brasília: Senado Federal, Coordenação de Edições Técnicas.

Brasil (1990). Lei n. 8.069 - Estatuto da Criança e do Adolescente. Brasília: Diário Oficial da União. 
Research, Society and Development, v. 10, n. 3, e12810313141, 2021

(CC BY 4.0) | ISSN 2525-3409 | DOI: http://dx.doi.org/10.33448/rsd-v10i3.13141

Brasil (1996). Lei n. 9.394 - Diretrizes e Bases da Educação Nacional. Brasília: Diário Oficial da União.

Brasil (1998). Referencial Curricular Nacional para a Educação Infantil. Brasília: Ministério da Educação e Cultura.

Brasil (2003). Lei n. 10.639 - inclui no currículo oficial da Rede de Ensino a obrigatoriedade da temática História e Cultura Afro-Brasileira, e dá outras providências. Brasília: Diário Oficial da União.

Brasil (2004). Diretrizes Curriculares Nacionais para a Educação das Relações Étnico-Raciais e para o Ensino de História e Cultura Afro-Brasileira e Africana. Brasília: Ministério da Educação e Cultura.

Brasil (2010). Diretrizes Curriculares Nacionais para Educação Infantil. Brasília: Ministério da Educação e Cultura.

Brasil (2013). Plano nacional de implementação das Diretrizes Curriculares Nacionais para Educação das Relações Étnico-Raciais e para o Ensino de História e Cultura Afro-Brasileira e Africana. Brasília: Ministério da Educação e Cultura.

Brasil (2017). Base Nacional Comum Curricular. Brasília: Ministério da Educação e Cultura.

Caldeira, L. B. (2010). O conceito de infância no decorrer da história. Paraná: Educadores.

Cavalleiro, E. S. (2017). Do silêncio do lar ao silêncio escolar: racismo, preconceito e discriminação na educação infantil. (6a ed.). Contexto.

Gil, A. C. (2017). Como elaborar projeto de pesquisa (6a ed.). Atlas.

Gomes, D. (2015). História da criança: breves considerações sobre concepções e escolarização da infância. In: XII Encontro Nacional De Educação. Curitiba: $\mathrm{PUC} / \mathrm{PR}$

Gomes, N. L.; Oliveira, F. S.; \& Souza, K. C. C. (2010). Diversidade étnico-racial e trajetórias docente: um estudo etnográfico em escolas públicas. In: Abramowicz, A. \& Gomes, N. L. Educação e raça: perspectivas políticas, pedagógicas e estéticas. Belo Horizonte: Autêntica. p. $57-73$.

Malheiro, J. (2005). Projeto político-pedagógico: utopia ou realidade? Ensaio: Avaliação e Políticas Públicas em Educação, 13 (46), $79-104$.

Minayo, M. C. S. (2017). Pesquisa social: teoria, método e criatividade. Petrópolis: Vozes.

Oliveira, B. C. de, \& Lindner, E. L. (2020). Ensino de Ciências e as relações Étnico-Raciais: um olhar para a Base Nacional Comum Curricular. Research, Society and Development, 9 (10), e3379108539, 1-25.

Paschoal, J. D. \& Machado, M. C. G. (2009). A História da Educação Infantil no Brasil: Avanços, retrocessos e desafios dessa modalidade educacional. Revista HistedBR Online, 9 (33), 78-95.

Rocha, R. M. C. (2007). Educação das relações étnico-raciais: pensando referenciais para a organização da prática pedagógica. Belo Horizonte: Mazza Edições.

Schaffrath, M. A. S (2000). Profissionalização do magistério feminino: uma história de emancipação e preconceitos. In: $23^{a}$ Reunião Anual da Associação Nacional de Pós-Graduação e Pesquisa em Educação. Caxambu: Anped.

Silva, A. M. \& Oliveira, M. R. F. (2014) A relevância da formação continuada do(a) professor(a) de Educação Infantil para uma prática reflexiva. In: III Jornada de Didática - II Seminário de Pesquisa do CEMAD. Londrina: Universidade Federal de Londrina.

Silva, P. B. G. (2018). Educação das Relações Étnico-Raciais nas instituições escolares. Educar em Revista, 34 (69), $123-150$.

Souza, C. A. B. (2015). Concepção de infância em Philippe Ariès. Monografia: Pedagogia, Universidade Estadual de Londrina.

Veiga, I. P. A. (2003). Inovações e projeto político-pedagógico: uma relação regulatória ou emancipatória? Cadernos Cedes, 23 (61), $267-281$.

Veiga, I. P. A. (2013). Projeto Político-Pedagógico da Escola: Uma construção coletiva. In: Veiga, I. P. A. Projeto Político Pedagógico da escola. São Paulo: Papirus. 11-35.

Veiga, I. P. A. \& Resende, L. M. G. (2008). Escola do projeto político pedagógico. Papirus. 